\title{
Post-thyroidectomy Neck Hematoma 10 Days after Hemithyroidectomy and Ipsilateral Parathyroidectomy: A Case Report with Dramatical Course
}

Gerd Wimmer $^{*}$, Beatrice Häussler ${ }^{1}$, Martin Eberwein ${ }^{2}$, Dietmar Öfner-Velano ${ }^{2}$ and Rupert Prommegger ${ }^{3}$

${ }^{1}$ Department of Visceral, Transplant and Thoracic Surgery/Department of Pediatric Surgery. Innsbruck Medical University, Innsbruck, Austria ${ }^{2}$ Department of Visceral, Transplant and Thoracic Surgery, Innsbruck Medical University, Innsbruck, Austria ${ }^{3}$ Sanatorium Kettenbrücke GmbH, Innsbruck, Austria

Abstract

Introduction: Post-thyroidectomy neck hematoma is one of the most feared and dangerous complications in thyroid surgery leading to airway obstruction and, if diagnosed and treated too late, fatal outcome may result. For prevention most crucial is effective intraoperative hemostasis. Additionally the patient should avoid physical strain. In case of post-thyroidectomy acute bleeding immediate airway protection is essential. Sometimes even bedside evacuation of hematoma is live saving. Neck hematoma more than 24 hours after thyroid surgery, as in our case, is rare.

Case Report: In a 56-year old female, 10 days after hemithyroidectomy and ipsilateral parathyroidectomy on the right side a post surgical neck hematoma arose. At that time the patient stayed in our region on holiday for skiing in a mountain skiresort about $100 \mathrm{~km}$ away from our clinic. Emergency doctor on site did not intubate her and took her to our medical university hospital, although the next hospital would have been $25 \mathrm{~km}$ closer. On arrival the patient was already hard breathing, unable to speak and swallow. Immediate intubation via videolaryngoscopy by an experienced senior anaesthesiologist succeeded. Due to major edema of the upper airway the patient had to be remained intubated for 3 days after reoperation. Seven days after the event the patient could be discharged from hospital.

Conclusion: Post-thyroidectomy neck hematoma more than 24 hours after surgery is rare. Misinterpretation of the life-threatening situation may lead to major complications as apallic syndrome or even death. Immediate protection of the airway by intubation is essential.

\section{Introduction}

Post-thyroidectomy neck hematoma belongs to the most dangerous complications in thyroid surgery. It leads to respiratory distress by airway obstruction, and, if diagnosed and treated too late, subsequently severe brain damage may occur or at worst can lead to death. Intraoperative effective hemostasis is an important goal for every surgeon to prevent this life-threatening complication. In the early days of thyroid surgery bleeding was generally a major problem [1]. Samuel Gross, Professor of Surgery at Jefferson Medical College in Pennsylvania described the state of thyroidectomy in 1866 "a horrid butchery". Emil Theodor Kocher was the first surgeon using precise surgical techniques for hemostasis and reduced mortality rate from $45 \%$ to about $0.5 \%$ in more than 5000 thyroid operations [2] $(0.18 \%$ in about 7000 thyroid operation [3]). Nowadays, postoperative neck hematoma occurs in approximately $1 \%$ after thyroid surgery [4] and the majority of these events happens in the first 6 hours [4]. About $20 \%$ occur 6 to 24 hours postoperatively [5]. Neck hematomas after 24 hours, as in our case, are rare [6]. In case of neck hematoma after surgery accompanied by respiratory distress, immediate protection of the airway by intubation is essential before reoperation. Sometimes even emergency "bedside evacuation" of the hematoma is necessary and protects the patient from fatal outcome. Intubation should be performed by the most experienced anaesthesiologist available, because significant edema of the epiglottis and the arytenoid may allready be present [7]. In our hospital we strongly recommend patients to avoid physical strain after thyroidectomy for 2 weeks. Till now no case of late hematoma (more than $24 \mathrm{hrs)}$ after thyroid surgery is reported, according to our hospital data.

\section{Case Report}

In a 56-year-old healthy female, 10 days post hemithyroidectomy and ipsilateral parathyroidectomy on the right side, a swelling of the
Publication History:

Received: February 19, 2018

Accepted: April 14, 2018

Published: April 16, 2018

\section{Keywords:}

Post-thyroidectomy hematoma, Protection of airway, Intubation, Edema neck, in terms of post thyroidectomy bleeding developed within a short time period during the night. Surgery was performed in another hospital and right afterwards the patient was on holiday for skiing in a mountain skiresort about $100 \mathrm{~km}$ away from our tertiary hospital. At about 3:00 in the morning the patient awoke because of a feeling of tightness in her throat but went on sleeping. About 2 hours later she awoke again, the tightness in her throat was much more intense, breathing and swallowing became harder. She also noticed a swelling of the neck and emergency doctor was called. At the arrival blood pressure was 141/84, pulse 106; $\mathrm{SpO}_{2} 93 \%$. The emergency doctor treated the patient with prednisolone $250 \mathrm{mg}, 10 \mathrm{mg}$ metoclopramide hydrochloride and $5 \mathrm{mg}$ tropisetron. At departure to hospital blood pressure was 166/74; pulse 93; $\mathrm{SpO}_{2} 98 \%$ with oxygen (2l/min). No attempt of intubation was made at that time. As helicopter transport was not available during night, the patient had to be transported on ground for $100 \mathrm{~km}$. On arrival in our clinic the patient presented with swollen neck, hard breathing and almost unable to swallow and speak. The emergency team of our hospital was called immediately by the endocrine surgeon and intubation could be managed luckily under provision of technical assistance with videolaryngoscopy and in standby for evacuation of hematoma and tracheostoma bedside. During following evacuation and exploration of the neck in the operating theatre, arterial bleeding of a branch of the inferior thyroid

*Curresponding Author: Dr. Gerd Wimmer, Department of Visceral, Transplant and Thoracic Surgery/Department of Pediatric Surgery. Innsbruck Medical University, Innsbruck, Austria, Tel: +43 512504 80763; Email: gerd.wimmer@tirol-kliniken.at

Citation: Wimmer G, Häussler B, Eberwein M, Öfner-Velano D, Prommegger R, et al. (2018) Post-thyroidectomy Neck Hematoma 10 Days after Hemithyroidectomy and Ipsilateral Parathyroidectomy: A Case Report with Dramatical Course. Int J Surg Surgical Porced 3: 136. https://doi.org/10.15344/2456-4443/2018/136

Copyright: (c) 2018 Wimmer et al. This is an open-access article distributed under the terms of the Creative Commons Attribution License, which permits unrestricted use, distribution, and reproduction in any medium, provided the original author and source are credited. 
Citation: Wimmer G, Häussler B, Eberwein M, Öfner-Velano D, Prommegger R, et al. (2018) Post-thyroidectomy Neck Hematoma 10 Days after Hemithyroidectomy and Ipsilateral Parathyroidectomy: A Case Report with Dramatical Course. Int J Surg Surgical Porced 3: 136. https://doi.org/10.15344/2456-4443/2018/136

Page 2 of 3

artery could be detected and closed by ligation. After operation a computed tomography was performed. It showed the lumen of the trachea in the neck area just kept braced by the tubus, the surrounding structures, larynx, hypopharynx and parts of the oropharynx heavily edematous as shown by figure 1,2,3 and 4 . The following treatment took place in the intensive care unit. Medication with prednisolone $500 \mathrm{mg}$ on the first day, $250 \mathrm{mg}$ on the second day, and cryotherapie was applied to reduce edema. Frequent control examinations of otorhinolaryngologists were performed to verify reduction of swelling and to evaluate the possibility for safe extubation. Three days after the event the attempt to remove the tracheal tubes, again with standby of an otorhinolaryngologist, succeeded. Laryngoscopy before extubation showed reduced swelling in the area of the supraglottis, epiglottis and the aryepiglottic plication to the arytenoid. Additionally, hematoma without swelling on the rear of the throat and severe hematoma of the vocal cords was found. The patient stayed another day under observation at the intensive care unit. On the fourth day the patient was transfered to the intermediate care unit of our department because she was still not able to cough up residual secretion out of the respiratory tract. On the next day clinical status improved and she was transfered again to normal ward. Another laryngoscopic control showed partial remission of the hematoma of the vocal cords. Seven days after the event the patient could be discharged from hospital (Time table).

09.11 .2011

19.11.2011 3:00

5:00

$5: 30$

hemithyroidectomy on the right side and ipsilateral parathyroidectomy

thightness in throat

thightness in throat much more intense, breathing and swallowing harder; emergency doctor called approach of emergency doctor no intubation (not much experience in intubation); RR 141/84, P 106; SpO2 93\%; prednisolone $250 \mathrm{mg}, 10 \mathrm{mg}$ metoclopramidehydrochloride and $5 \mathrm{mg}$ tropisetrone; Diagnosis: „dyspnoea because of external cervical bleeding"

$\rightarrow$ Departure to University Hospital of Innsbruck (102 $\mathrm{km}, 20$ minutes longer than to nearest hospital)

7:45 Arrival in clinic; swollen neck, hard breathing, almost unable to swallow and speak;

$\rightarrow$ intubation via videolaryngoscopy evacuation of the hematoma in the operating theatre; arterial bleeding of a branch of the inferior thyroid artery could be detected and closed by ligature

14:22 CT of the neck

Examination by otorhinolaryngologist: prednisolone $500 \mathrm{mg}$

20.11.2011 Examination by otorhinolaryngologist: prednisolone $250 \mathrm{mg}$

21.11.2011 attempt to extubate under control and standby of an otorhinolaryngologist in the operating theatre. Laryngoscopy before extubation:

1.

3.

22.11.2011

23.11.2011

25.11.2011

26.11.2011 reduced swelling in the area of the supraglottis, epiglottis and the aryepiglottic plication to the arytenoid

hematoma without swelling on the rear of the throat severe hematoma of the vocal cords

$\rightarrow$ removal of the tracheal tubus

transfer to intermediate care unit

laryngoscopic control: partial remission of the hematoma of the vocal cords

discharged from hospital transfer to ward

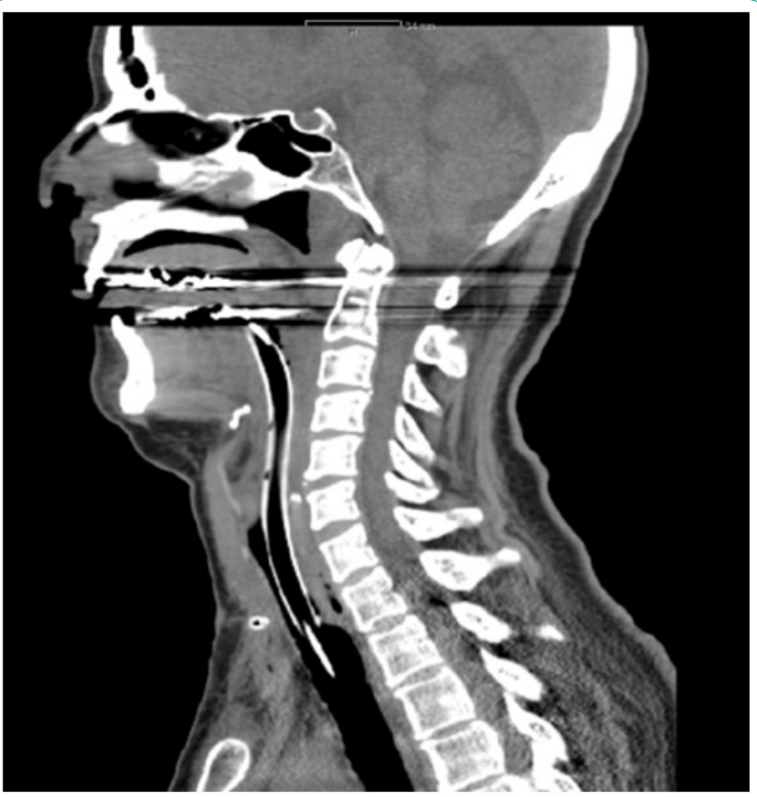

Figure 1: Picture 1: postoperative CT-scan: Larynx, hypopharynx and parts of the oropharynx heavily edematous.

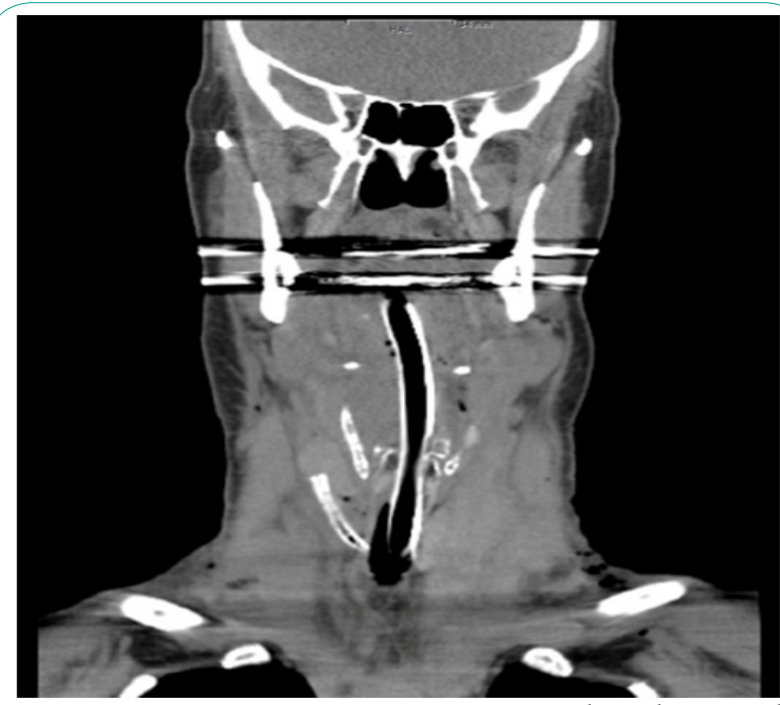

Figure 2: Picture 2: postoperative CT-scan: Larynx, hypopharynx and parts of the oropharynx heavily edematous. Lumen of trachea in the neck area just kept braced by the tubus.

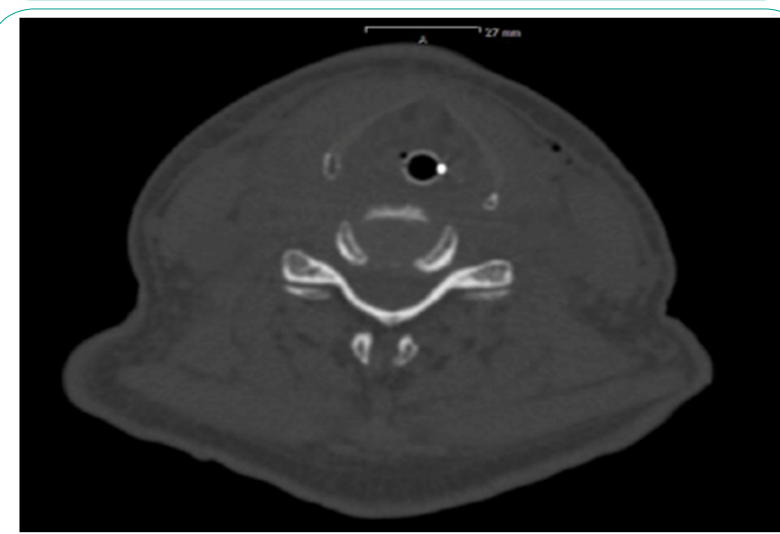

Figure 3: Picture 3: postoperative CT-scan: Larynx, hypopharynx and parts of the oropharynx heavily edematous. Lumen of trachea in the neck area just kept braced by the tubus. 
Citation: Wimmer G, Häussler B, Eberwein M, Öfner-Velano D, Prommegger R, et al. (2018) Post-thyroidectomy Neck Hematoma 10 Days after Hemithyroidectomy and Ipsilateral Parathyroidectomy: A Case Report with Dramatical Course. Int J Surg Surgical Porced 3: 136. https://doi.org/10.15344/2456-4443/2018/136

Page 3 of 3

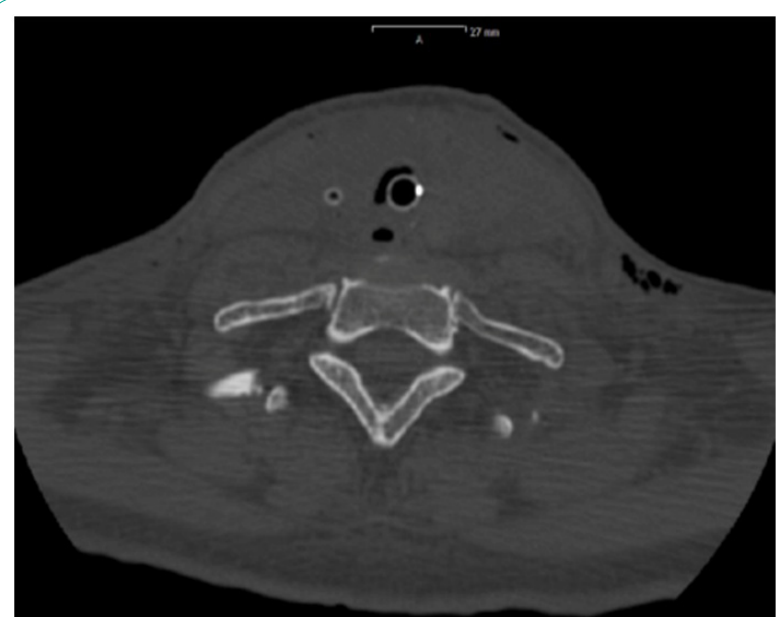

Figure 4: Postoperative CT-scan: neck area heavily edematous.

\section{Discussion}

Now a days neck hematoma occurs in approximatly $0.1 \%$ to $1.1 \%$ after thyroid surgery [5] and late post-thyroidectomy neck hematoma is an absolutely rare event. New surgical techniques and especially improvement of devices for sealing vessels help to avoid post surgical bleeding. Operating strategies are reconsidered to minimize morbidity. For example, some studies advise against prophylactic central neck dissection in case of differentiated thyroid carcinoma less than $10 \mathrm{~mm}$ of diameter and clinically lymph node negative, because it may increase postoperative complications without any demonstrable benefits in terms of long-term survival $[8,9]$. Structured postoperative monitoring of the patients leads, in case of hematoma, to early diagnosis and treatment in clinical setting. However, as a result of this dangerous complication a rare number of patients suffer from apallic syndrome per year. Cough, valsalva maneuver [10] and also physical strain-for example carring heavy luggage -leads to high pressure in the vessels of the head and neck causing after bleeding. This can also happen by rapid movement or accidents in sports. In the guidelines of our endocrine unit we recommend to refrain from physical strain for at least 2 weeks after thyroidectomy. Because the outcome of bleeding after thyroidectomy is much worse and life-threatening outside of clinical setting, and often initially a result of underestimation by physicians because of lack of experience with a long approach to expert help. In this case report the patient recovered luckily without any related complications and long-term health damage.

\section{Conclusion}

Post-thyroidectomy neck hematoma evolving more than 24 hours after surgery is rare. Outside of clinical setting misinterpretation of the situation and long approach to expert help may lead to major complications and even death. Immediate protection of the airway by intubation is essential.

\section{Competing Interests}

The authors declare that no competing interests exist.

\section{Funding}

Department of Visceral, Transplant and Thoracic Surgery/ Department of Pediatric Surgery. Innsbruck Medical University, Innsbruck, Austria

\section{References}

1. Materazzi G, Ambrosini CE, Fregoli L, Napoli LD, Frustaci G, et al. (2017) Prevention and management of bleeding in thyroid surgery. Gland Surg 6: 510-515.

2. Hannan SA (2006) The magnificent seven: a history of modern thyroid surgery. Int J Surg 4: 187-191.

3. Chigot JP (2000) Theodor Emil Kocher, modern surgery pioneer. Ann Chir 125: 884-892.

4. Terris DJ, Snyder S, Carneiro-Pla D, Inabnet WB 3rd, Kandil E, et al. (2013) American Thyroid Association statement on outpatient thyroidectomy. Thyroid 23: 1193-202.

5. Shaha AR, Jaffe BM (1994) Practical management of post- thyroidectomy hematoma. J Surg Oncol 57: 235-238.

6. Rosenbaum MA, Haridas M, McHenry CR (2008) Life-threatening neck hematoma complicating thyroid and parathyroid surgery. The American Journal of Surgery 195: 339-343.

7. Mittendorf EA, McHenry CR (2004) Complications and sequelae of thyroidectomy and an analysis of surgeon experience and outcome. Surg Technol Int 12: 152-157.

8. Calò PG, Conzo G, Raffaelli M, Medas F, Gambardella C, et al. (2017) Total thyroidectomy alone versus ipsilateral versus bilateral prophylactic central neck dissection in clinically node-negative differentiated thyroid carcinoma. A retrospective multicenter study. Eur J Surg Oncol 43: 126-132.

9. Conzo G, Mauriello C, Docimo G, Gambardella C, Thomas G, et al. (2014) Clinicopathological pattern of lymph node recurrence of papillary thyroid cancer. Implications for surgery. Int J Surg 12: 194-1977.

10. Suzuki S, Yasunaga H, Matsui H, Fushimi K, Saito $Y$, et al. (2016) Factors Associated With Neck Hematoma After Thyroidectomy, A Retrospective Analysis Using a Japanese Inpatient Database. Medicine 95: 1-7. 